2017-05-11

\title{
Microstructure correlation with formability for biaxial stretching of magnesium alloy AZ31B at mildly elevated temperatures
}

\author{
David T. Fullwood \\ Brigham Young University, dfullwood@byu.edu \\ Isaac Chelladurai \\ Brigham Young University Mechanical Engineering, isaac.c@byu.edu \\ Michael P. Miles \\ Brigham Young University Manufacturing Engineering Technology, mmiles@byu.edu \\ John E. Carsley \\ General Motors R\&D \\ Raj K. Mishra \\ General Motors R\&D \\ Follow this and additional works at: https://scholarsarchive.byu.edu/facpub

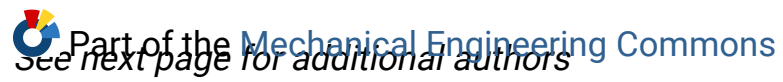 \\ Original Publication Citation \\ Chelladurai, I., Miles, M.P., Fullwood, D.T. et al. JOM (2017) 69: 907. doi:10.1007/ \\ s11837-017-2309-7
}

\section{BYU ScholarsArchive Citation}

Fullwood, David T.; Chelladurai, Isaac; Miles, Michael P.; Carsley, John E.; Mishra, Raj K.; Beyerlein, Irene J.; and Knezevic, Marko, "Microstructure correlation with formability for biaxial stretching of magnesium alloy AZ31B at mildly elevated temperatures" (2017). Faculty Publications. 1864.

https://scholarsarchive.byu.edu/facpub/1864

This Peer-Reviewed Article is brought to you for free and open access by BYU ScholarsArchive. It has been accepted for inclusion in Faculty Publications by an authorized administrator of BYU ScholarsArchive. For more information, please contact ellen_amatangelo@byu.edu. 


\section{Authors}

David T. Fullwood, Isaac Chelladurai, Michael P. Miles, John E. Carsley, Raj K. Mishra, Irene J. Beyerlein, and Marko Knezevic 


\section{Microstructure correlation with formability for biaxial stretching of magnesium alloy AZ31B at mildly elevated temperatures}

${ }^{1}$ Isaac Chelladurai*, ${ }^{2}$ Michael P. Miles, ${ }^{1}$ David T. Fullwood, ${ }^{3}$ John E. Carsley, ${ }^{3}$ Raj K. Mishra, ${ }^{4}$ Irene J. Beyerlein, and ${ }^{5}$ Marko Knezevic

${ }^{1}$ Brigham Young University, Mechanical Engineering, 435 CTB, Provo, UT 84602.

${ }^{2}$ Brigham Young University, Manufacturing Engineering Technology, 265 CTB, Provo, UT 84602

${ }^{3}$ General Motors R\&D, Warren, MI 48090

${ }^{4}$ Theoretical Division, MS B16, Los Alamos National Laboratory, Los Alamos, NM 87545, USA

${ }^{5}$ Department of Mechanical Engineering, University of New Hampshire, Durham, NH 03824, USA

Keywords: Magnesium alloy, microstructure, formability, biaxial loads.

*Corresponding author: isaac.c@byu.edu 


\begin{abstract}
Magnesium AZ31B sheets of $2 \mathrm{~mm}$ thickness were stretch formed using a $101.6 \mathrm{~mm}$ diameter punch at temperatures from $25^{\circ} \mathrm{C}-150^{\circ} \mathrm{C}$, in $25^{\circ} \mathrm{C}$ increments. Surface strains were measured using a digital image correlation (DIC) method. The punch height vs load curve was found to be the same for temperatures of $25^{\circ} \mathrm{C}$ and for $50^{\circ} \mathrm{C}$, while at $75^{\circ} \mathrm{C}$ and above the load for a given punch height started to decrease, indicating a potential change in deformation mechanism. Electron Backscatter Diffraction (EBSD) was used to quantify features of the microstructure in the tested specimens. In particular, the gradual decrease in twinning activity due to easier thermally activated slip with increasing temperatures is quantified across this range. Moreover, twin activity was found to predominantly involve the formation of $\{10 \overline{1} 1\}$ compression twins that rapidly transform to create secondary twins for easier strain accommodation.
\end{abstract}

\title{
Introduction
}

Magnesium and its alloys undergo only moderate amounts of plasticity at room temperature before fracture. One particular alloy, AZ31B, is a strong contender for light weighting applications in the auto body structure. However, the HCP crystal structure of magnesium has only one close packed plane (basal plane) and when deformed, slip on these close packed planes does not provide the required number of independent deformation modes needed for an arbitrary shape change [1] causing a lack in ductility at room temperature. Furthermore, at room temperature, strong basal texture of the rolled Mg sheet with the c-axis direction largely perpendicular to the plane of the sheet leads to insufficient strain accommodation through the thickness. For this alloy, it has been suggested that twinning, and more particularly compression twinning, is the primary mechanism for through-thickness contraction deformation [2, 3]. The evolution of microstructure for a range of temperatures has been previously explored for the AZ31B alloy [4], and improved ductility has been observed in various Mg alloys at elevated temperatures[5-7]. Barnett explained this as a result of enhanced activity of non-basal slip [8]. Other studies also demonstrate how twinning could favorably assist in improving the ductility of HCP materials [9, 10]. This study seeks to quantify slip and twin activity for the AZ31B alloy across this moderately elevated temperature range under a biaxial load in order to provide insight into the observed improvement in ductility with increase in temperature.

Many studies have used a variety of methods to understand correlations and behavior at the microstructural level for magnesium. For example, formability and failure mechanisms for Mg alloys deformed in uniaxial tension, uniaxial compression and biaxial tension have been studied for the purpose of establishing crack initiation sites and investigating the relationship between strain path and the failure initiation mechanism [11, 12]. Other articles have investigated these correlations to better predict twinning events [13-18]. But a more detailed investigation on the microstructural features relating to the transition from twin activity to the various slip modes (including non-basal slip) is needed. One approach to establishing these correlations utilized recent advances in cross-correlation electron backscatter diffraction (EBSD) to observe microstructure changes after AZ31B specimens were deformed at various temperatures, in order to assess the potential to resolve slip activity onto the various possible planes [19].

In the present work, AZ31B sheets were stretched in biaxial tension using a limiting dome height die set at room temperature and subsequent increments of $25^{\circ} \mathrm{C}$ up to $150^{\circ} \mathrm{C}$. Changes in microstructure were then related to deformation mechanisms that were deduced from twin density, calculated as the ratio of the number of twins per unit area in each of the 
observed EBSD scans, and geometrically necessary dislocation (GND) content for each temperature. Though there have been studies on the influence of temperature on extension twins, as far as the authors are aware similar studies for compression twins are less common. Evidence of secondary twinning at lower temperatures is presented along with analysis of slip activity based on GND for different temperatures.

\section{Experimental Methods}

AZ31B sheets of $2 \mathrm{~mm}$ thickness were stretched over a $101.6 \mathrm{~mm}$ diameter hemispherical punch at temperatures ranging from $25^{\circ} \mathrm{C}-150^{\circ} \mathrm{C}$ (in increments of $25^{\circ} \mathrm{C}$ ). All sheet blanks had dimensions of approximately $200 \mathrm{~mm}$ x $200 \mathrm{~mm}$ to ensure that they were fully clamped. In addition, boron nitride lubricant was applied to the center of each specimen prior to forming, to reduce friction and promote biaxial stretching. The press was a double-action, servo-hydraulic press with a fully closed-loop control system consisting of a clamp rated at 68,000 kgf (75 tons) and a punch rated at 45,000 kgf (50 tons). The upper die and lower blank holder were heated to the target forming temperature with band heaters [20]. The upper and lower sections were enveloped in Cer-Wool ${ }^{\circledR}$ ceramic fiber to reduce heat loss during forming. A K-type thermocouple was used to measure the temperature of the blank prior to forming, where forming was initiated as soon as the target temperature was reached. Black and white ink was applied to each blank in a speckled pattern on one side of the sheet prior to forming and the resulting pattern allowed for the measurement of surface strains by a digital image correlation (DIC) method. Biaxial strain measurements were taken from the pole area as the sheets were stretched to punch heights of $4 \mathrm{~mm}$ and $6 \mathrm{~mm}$ for each temperature. After forming, specimens were cut from the pole area and prepared for EBSD by grinding with 1200 grit silicon carbide sheets, followed by electro polishing in an electrolyte consisting of $150 \mathrm{ml}$ 2-butoxyethanol, $30 \mathrm{ml}$ ethanol and $15 \mathrm{ml}$ perchloric acid (60\%) at a voltage of $17 \mathrm{kV}$. These samples were then etched with a solution of $60 \%$ ethanol, $20 \%$ water, $15 \%$ acetic acid and 5\% nitric acid prior to performing EBSD scans using a SEM microscope. Data from the EBSD scans were collected using OIM DC ${ }^{\circledR}$ software and analyzed using the TSL OIM Analysis ${ }^{\circledR}$ tool. For convenience, RD, TD and ND refer to the rolling direction, transverse direction and normal direction respectively. For example, a plane identified as an ND plane is one for which the normal is along the sheet normal direction.

To generate dislocation maps, the EBSPs (electron backscattered patterns) were post-processed. Using cross correlation techniques, the lattice perturbation between the neighboring scan points can be measured from their corresponding EBSPs from which relative elastic distortion, $\boldsymbol{\beta}$, can be measured, and hence the GND density can be deduced [19, 21-23]. The Nye tensor [24] aggregates dislocation activity from individual slip systems as follows:

$\alpha_{i j}=\sum_{m} \rho^{(m)} b_{i}^{(m)} v_{j}^{(m)}$

where $\rho$ is the dislocation density for GNDs of the $m^{\text {th }}$ dislocation system (defined here as a unique combination of Burgers vector and line vector for a pure edge or screw dislocation); $b$ is the Burgers vector and $v$ is the associated line vector. The measured distortion is related to the Nye tensor via [25]:

$\boldsymbol{\alpha}=\nabla \times \boldsymbol{\beta}$ 
Because this study uses 2D EBSD, derivatives normal to the sample surface are unavailable, meaning only the rightmost column of $\alpha$ is fully known. If strain is assumed to be negligible compared to lattice rotations, then an additional three degrees of freedom are available [26]. Because Mg has 36 possible slip systems and 27 unique dislocation systems, the problem of determining GND density is under-constrained. To find the most physical solution, typically the total line length of dislocations is minimized $[27,28]$. In this case, the dislocation densities were weighted by their critical resolved shear stress (CRSS) factor:

Minimize $f=\sum_{t=1}^{N}\left|w^{t} \rho^{t}\right|$, s.t. $\alpha_{i j}=\sum_{t=1}^{N} \rho^{m} b_{i}^{m} v_{j}^{m}$

where $w$ is the weight for the CRSS factor and $\mathrm{f}$ is the function to be minimized.

The $<\mathrm{c}+\mathrm{a}>$ to total slip ratio and the total dislocation density were then calculated from the individual dislocation system densities [29, 30]. The specimens for this study were cut such that the microscopy sample surface was perpendicular to the normal direction of the sheet in each case. This was done because the plastic effects of sheet thinning were being observed, and EBSD dislocation microscopy techniques work best on this plane of deformation [31, 32].

\section{Results}

DIC measurements of surface strains showed that stretching of the AZ31B sheets was almost perfectly biaxial for each temperature, as seen in Figure 1.

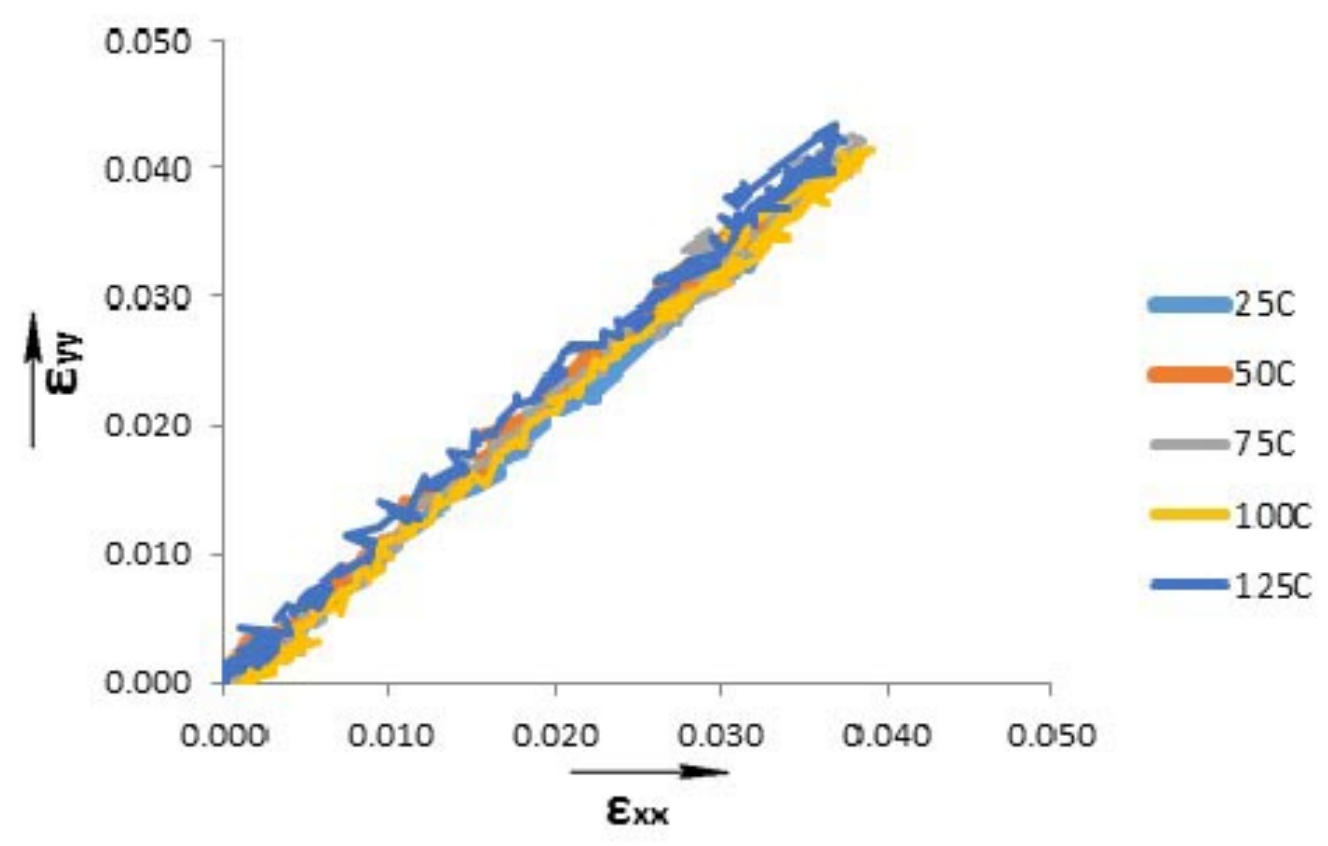

Fig 1: Strain paths for biaxial stretching experiments from $25^{\circ} \mathrm{C}$ to $125^{\circ} \mathrm{C}$. 
Strain in the $\mathrm{x}$ and $\mathrm{y}$ directions (in the plane of the sheet) were proportional for all punch displacements and across all forming temperatures indicating that the boron nitride lubricant was effective in minimizing friction between the punch and the sheets for all temperatures. Biaxial stretching was desired here because the AZ31B sheets had an initial strong basal texture and any stretching that occurred required immediate thinning of the sheet with a corresponding contraction of the c-axis at the level of the average grain.

As discussed in the introduction of this paper, the c-axis contraction in AZ31B at room temperature induces twinning to accommodate thinning strain, but there is no clear understanding of the relationship between twinning and slip as temperature rises. An interesting result from our biaxial stretching experiments is shown in Figure 2.

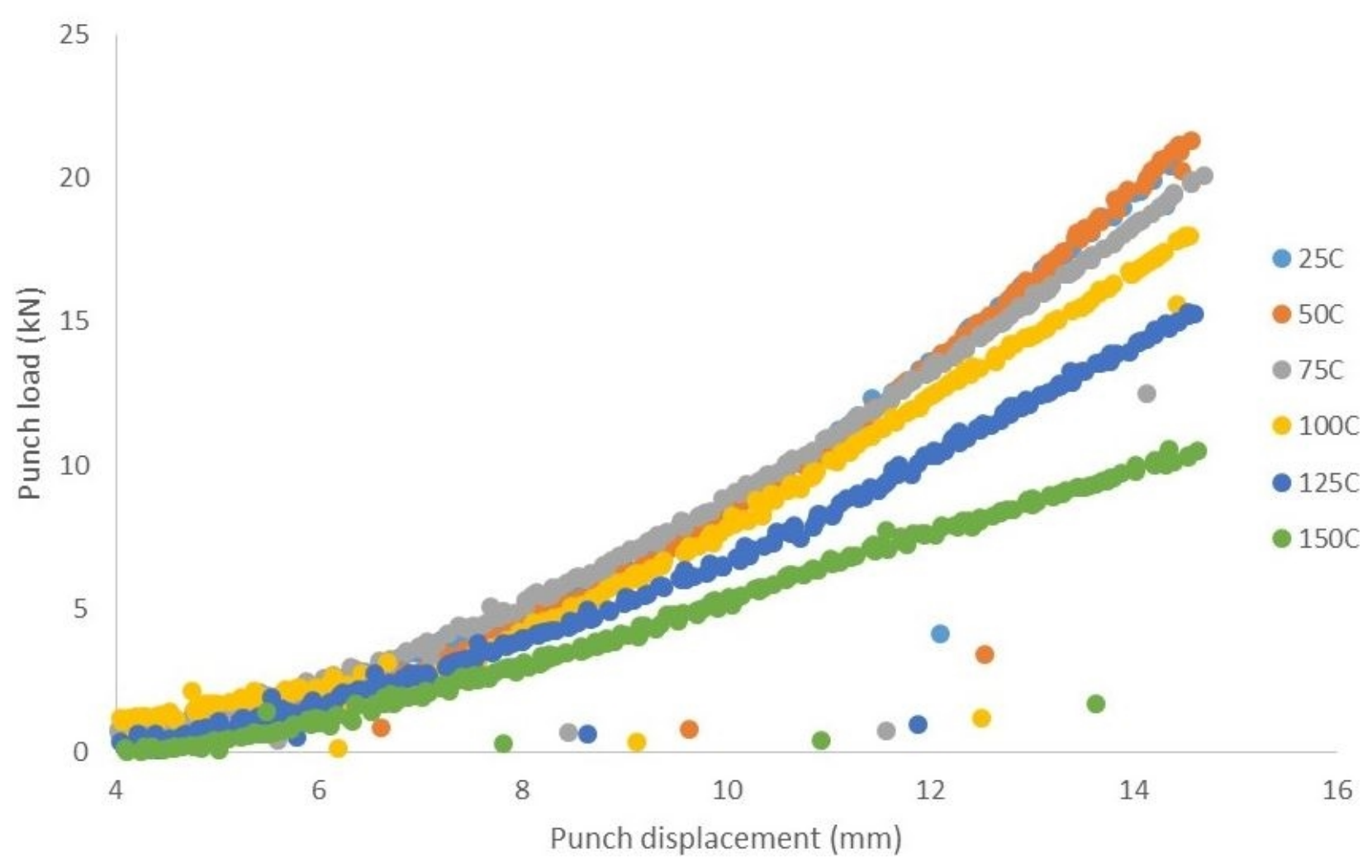

Fig 2: Load vs punch displacement for biaxial stretching experiments, from $25^{\circ} \mathrm{C}$ to $150^{\circ} \mathrm{C}$.

The punch load versus punch displacement curves are almost identical for $25^{\circ} \mathrm{C}$ and for $50^{\circ} \mathrm{C}$. At $75^{\circ} \mathrm{C}$ and with increasing temperature, the load increases with displacement at progressively decreasing rates. The decreasing loading curves observed between $50^{\circ} \mathrm{C}$ and $75^{\circ} \mathrm{C}$ might be explained by a reduction in the critical resolved shear stress for either contraction twinning, slip in the $<\mathrm{a}>$ direction, or possibly by slip in the $<\mathrm{c}+\mathrm{a}>$ direction. Similar results were found in prior work when forming limits of annealed AZ31B sheets were measured at $25^{\circ} \mathrm{C}, 75^{\circ} \mathrm{C}$, and $125^{\circ} \mathrm{C}[33]$.

In order to quantify the change between these two activities, micrographs of the biaxially strained specimens were examined, along with EBSD scans, to post process the scans and to measure twin density and GND content at the different forming temperatures. The microstructure reveals that contraction and double twins are predominant, but some tension twins 
are also present. The double twins are found to have an axis-angle combination of $\langle 11 \overline{2} 0\rangle$ and $38^{\circ}$. The primary twin variant was found to be a compression twin of type $\{10 \overline{1} 1\}$. The predominance of these twins has been observed in AZ31B in several studies [2, 34-37]. As can be seen in Figure 3, the overall twin density remains almost level with perhaps only a slight increase. For the purposes of this paper, the automated count of the various types of twins by the analysis tool is augmented with a manual count of twins not identified by the software, and this approach resulted in the overall twin density that was established for each scan.

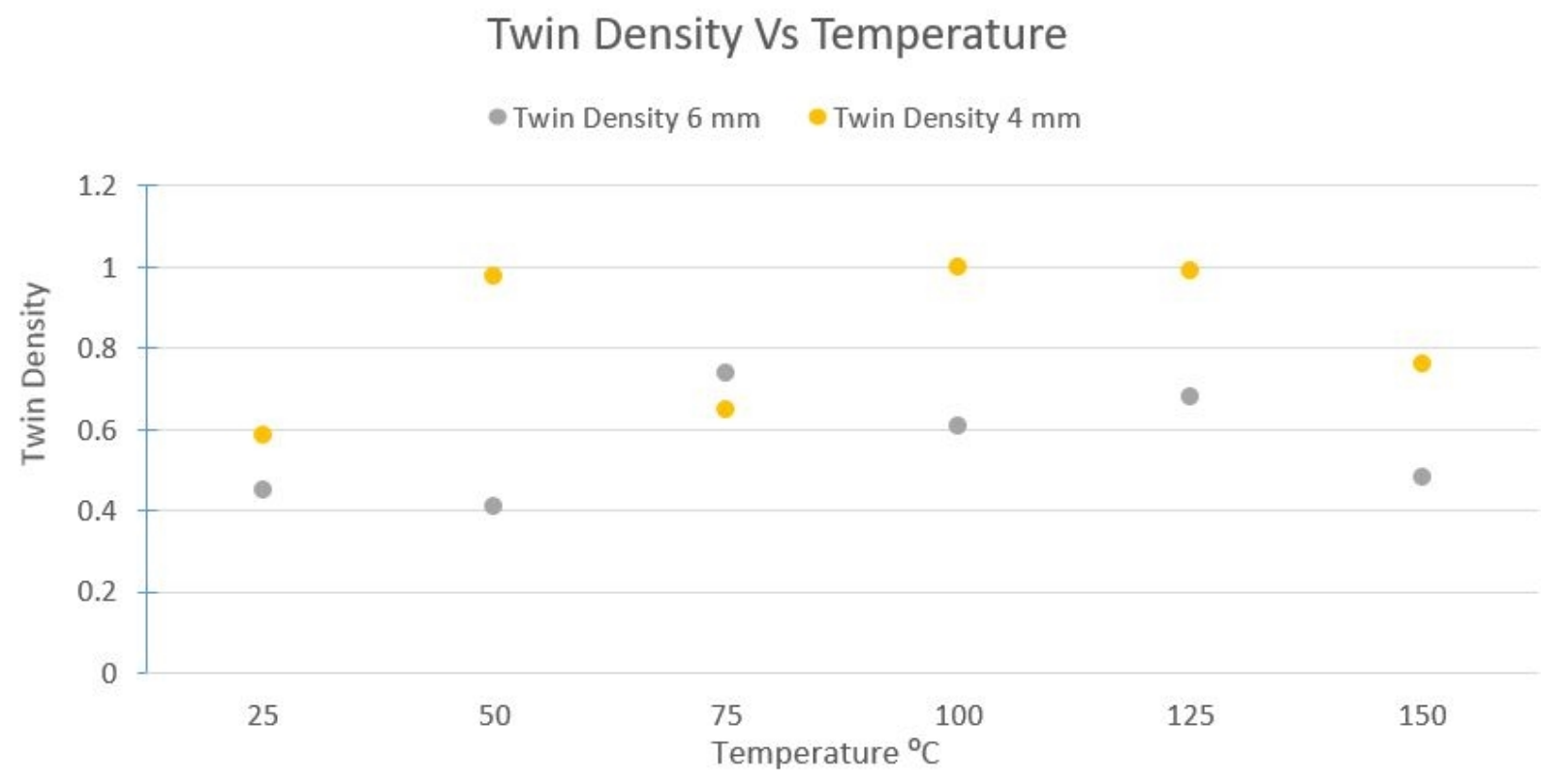

Fig 3: Twin density vs temperature for specimens deformed by LDH dome heights of $6 \mathrm{~mm}$ and $4 \mathrm{~mm}$.

The apparent noise in twin measurement does not allow for identifying a trend with temperature. It appears there could be a slight upward trend for both punch heights, but there is not enough data to draw a conclusion. Therefore, we make the assumption that twin density is essentially constant with temperature in these experiments. We would also expect a larger twin density with greater punch height, but it appears that the $4 \mathrm{~mm}$ sample data exhibit greater twin density than $6 \mathrm{~mm}$ sample data. This is likely also a result of twin density measurement error, which can be attributed to the TSL OIM Analysis® software being unable to identify all of the twins seen in the IPF maps. The primary twinning mechanism of $\{10 \overline{1} 1\}$ twins gives rise to thin twin lamellas within the grains and the $0.3 \mu \mathrm{m}$ step size used for the EBSD scan does not seem to be sufficient to define the twin areas with the required detail for the software to establish them as twins. Furthermore, the analysis tool does not have the capacity to identify secondary twins or double twins in the microstructure by default and even when programmed to find these twin systems, they are not identified entirely. Having said that, it is still successful in establishing the formation of double twins originating from within the initial compression twins. Compared to all of the twin types identified in the microstructures, the $\langle 11 \overline{2} 0\rangle 38^{\circ}$ double twins were the ones observed with the greatest frequency, for both specimens tested both punch heights and at all temperatures. The formation of these twins even at low temperatures is an interesting observation as it would mean that twin simulation models need to account for double twinning even at room temperature. 
To understand the evolution of twin structures with increasing temperatures, twin aspect ratios were studied. This was determined by first obtaining a "Twin Parent/Daughter" map generated by OIM Analysis (Figures 4 and 5) using definitions for the twin systems of interest and processing the resulting image in MATLAB to isolate regions classified as twins. In order to get a measurement of twin lengths and twin thickness, the twins are treated as elliptical areas where major and minor axes (representing twin length and twin thickness) were fitted to each twin. The aspect ratio was calculated for each twin as the minor axis divided by the major axis. An average was then taken. Size was determined by multiplying the number of pixels in each twin by a unit area of the step size squared. The results of this analysis did not show any significant changes in twin length or twin thickness for increasing temperatures. But the fact that the minor axis of contraction twins does not change significantly with temperature further supports the OIM analysis that indicated the presence of double twins. The rapid transition from contraction to double twins by the formation of extension twins within the initially formed contraction twins could be a dominant factor in influencing twin growth and shape evolution for AZ31B material under biaxial stretching. Upon formation of these extension twins, the contraction twin stops growing because of loss of coherency with the matrix leading to more opportunities of failure within the microstructure of AZ31B under such types of load [38]. However, a more detailed study with additional strain steps is required to observe trends in formation of twins earlier along the strain path.

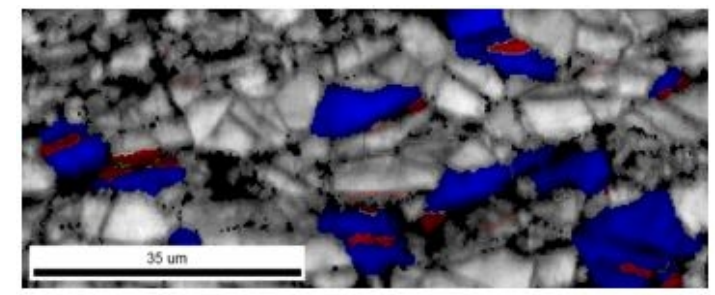

a

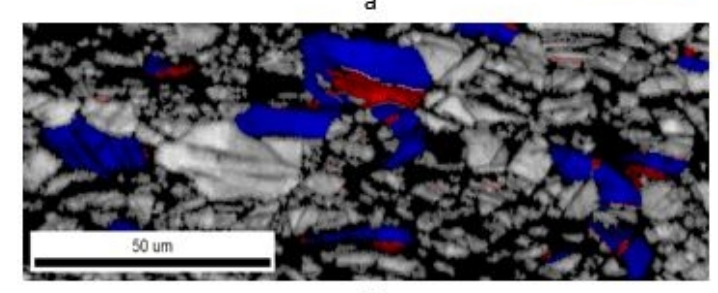

$\mathrm{c}$

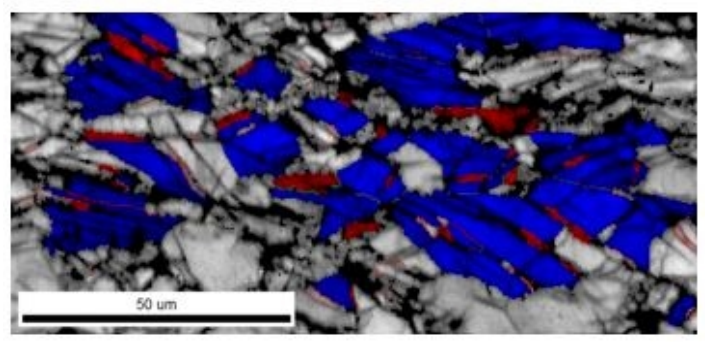

e

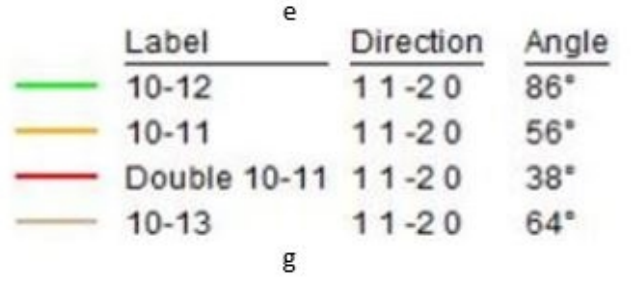

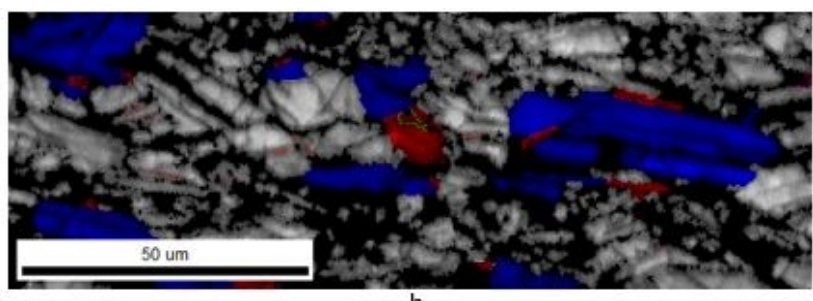

b

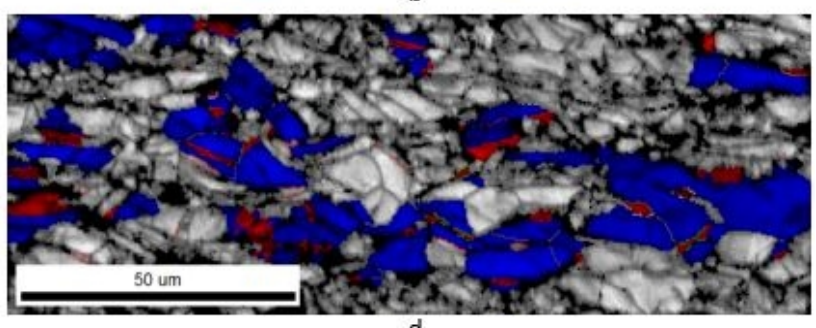

d

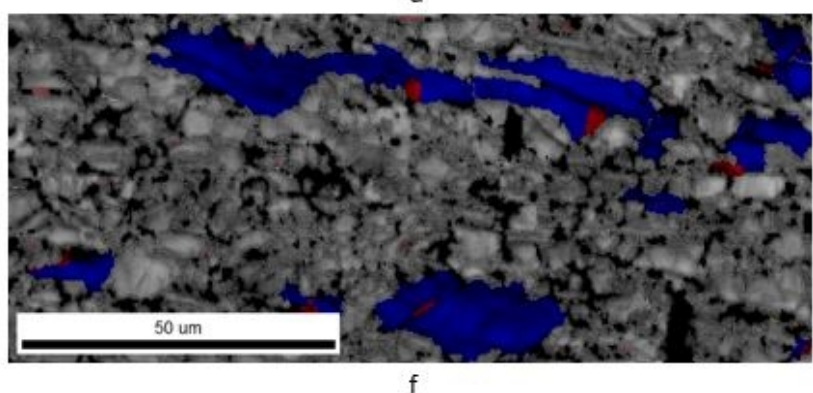

f

Fig 4: Twin parent maps of representative regions along on the ND plane after biaxial stretching for $6 \mathrm{~mm}$ of punch travel at (a) $25^{\circ} \mathrm{C}$, (b) $50^{\circ} \mathrm{C}$, (c) $75^{\circ} \mathrm{C}$, (d) $100^{\circ} \mathrm{C}$, (e) $125^{\circ} \mathrm{C}$ and (f) $150^{\circ} \mathrm{C}$. (g) Legends for different twin systems. 


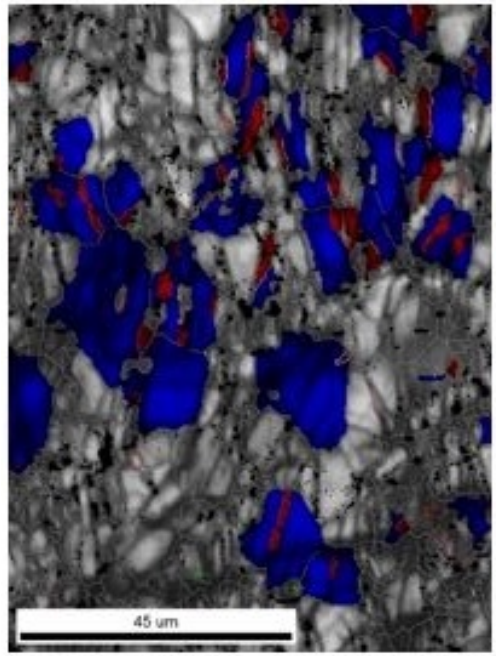

a
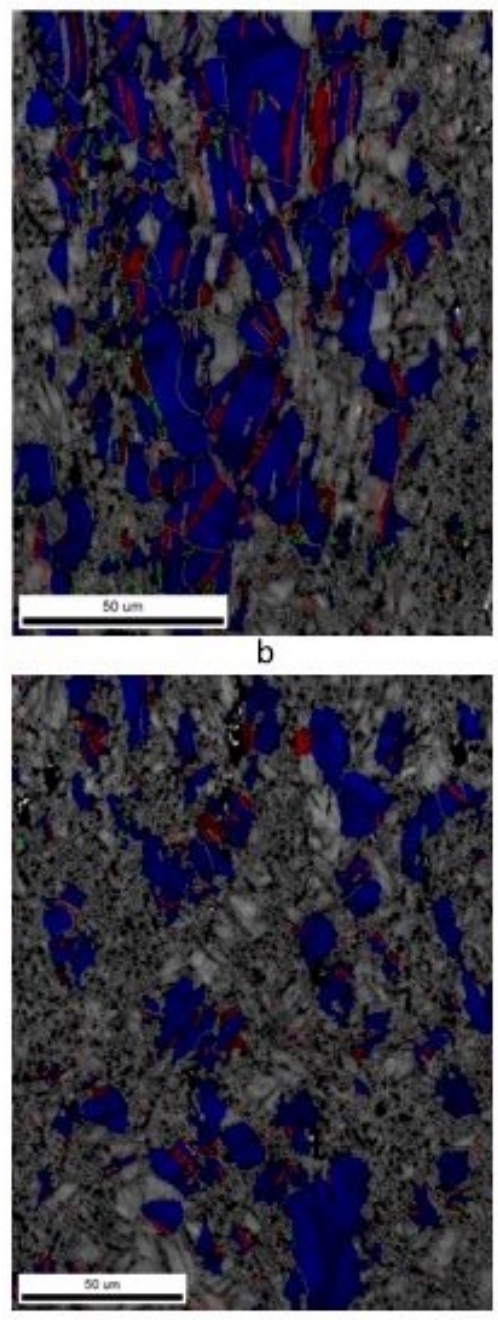

c

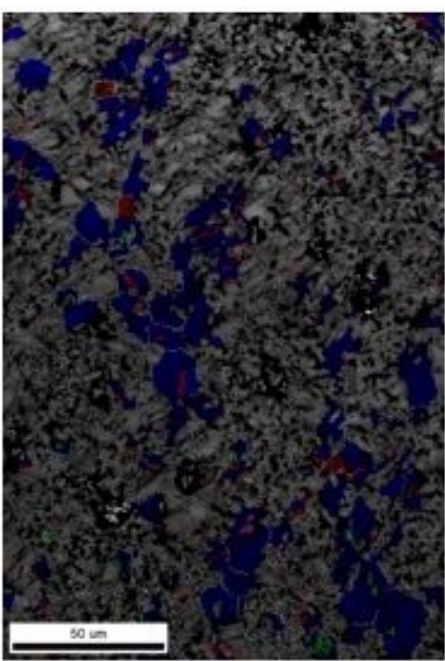

d

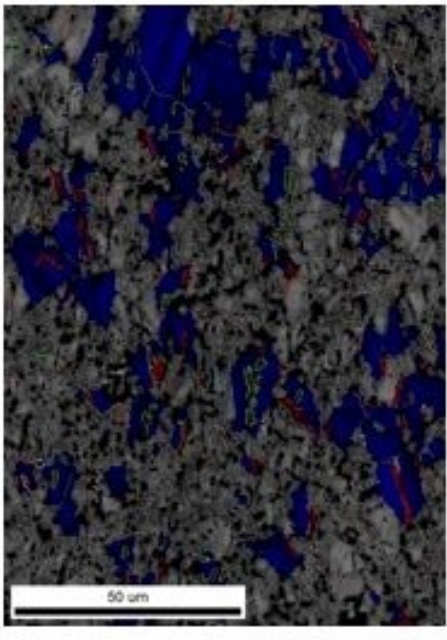

e

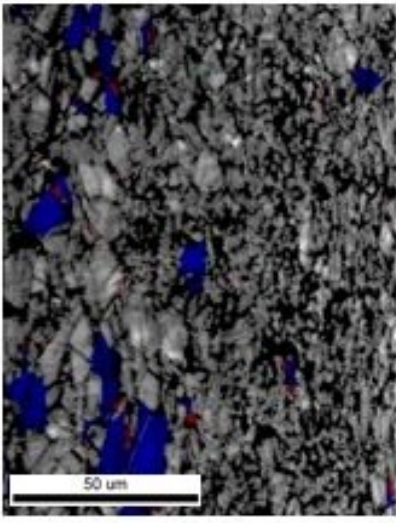

f

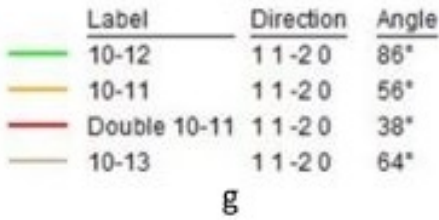

Fig 5: Twin parent maps of representative regions along the ND plane after biaxial stretching for $4 \mathrm{~mm}$ of punch travel at (a) $25^{\circ} \mathrm{C}$, (b) $50^{\circ} \mathrm{C}$, (c) $75^{\circ} \mathrm{C}$, (d) $100^{\circ} \mathrm{C}$, (e) $125^{\circ} \mathrm{C}$ and (f) $150^{\circ} \mathrm{C}$. (g) Legends for different twin system. 


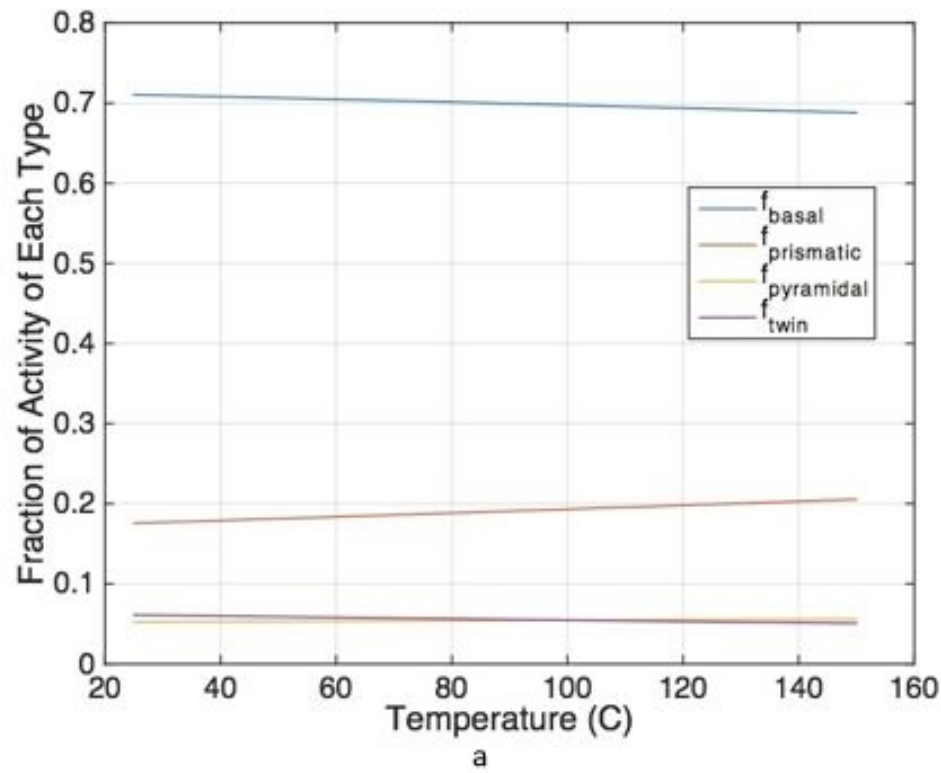

Slip activity Vs Temperature

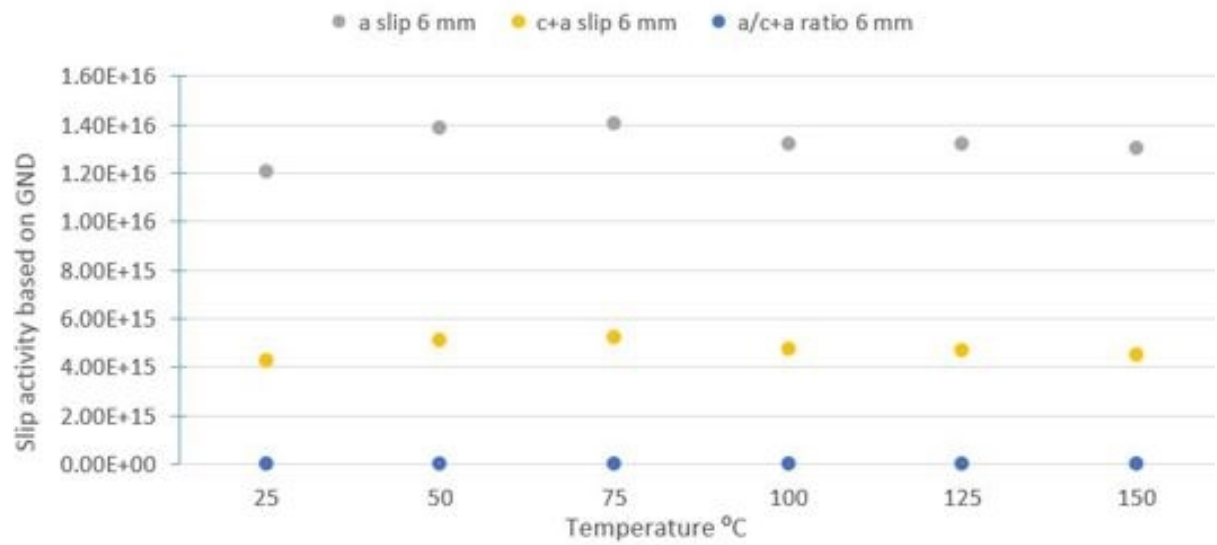

b

Slip activity Vs Temperature

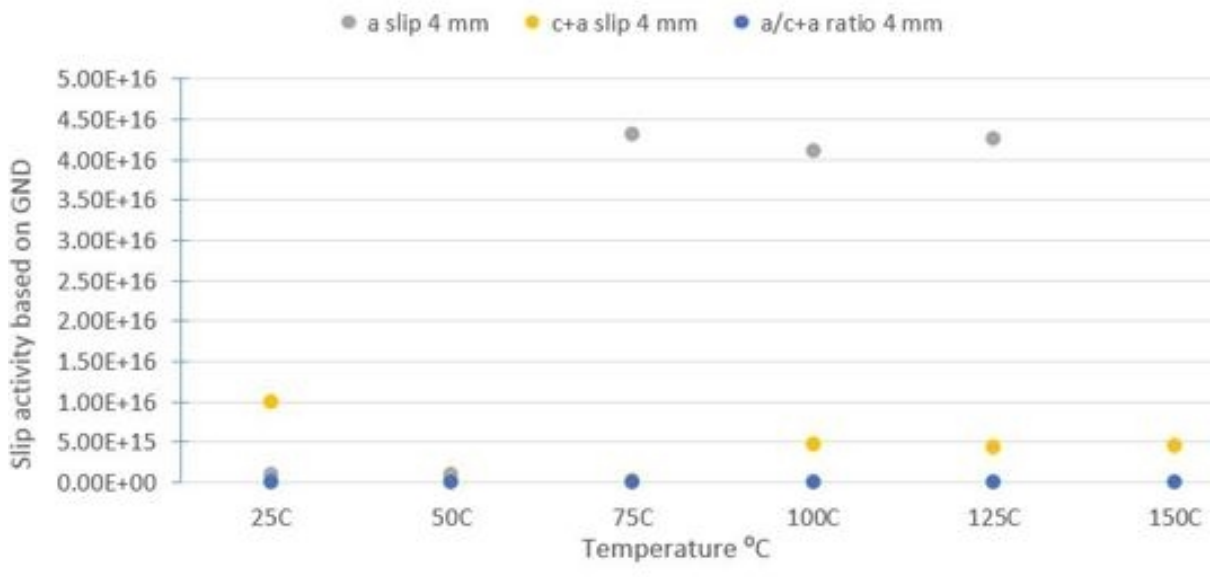

Fig 6: (a) Predicted relative slip and twinning activity as a function of forming temperature based upon a CRSS law. (b) Slip activity for the specimens deformed biaxially for $6 \mathrm{~mm}$ of punch travel at different temperatures. (c) Slip activity for the samples deformed biaxially for $4 \mathrm{~mm}$ of punch travel at different temperatures. 
In anticipation of quantifying both twin and slip activity during this study, relative activity of various deformation mechanisms in AZ31B were estimated as a function of temperature based upon predicted CRSS evolution with temperature from a recently published constitutive model [39]. The following temperature dependencies were used for the CRSS of AZ31B slip systems:

$\tau_{0}^{\text {basal }}=17 e^{(-T / 786)}, \tau_{0}^{\text {prism }}=108 e^{(-T / 359)}, \tau_{0}^{\text {pyram }}=290 e^{(-T / 489)}(\mathrm{MPa})$

where $\mathrm{T}$ is the temperature $(\mathrm{K})$. As per current literature, the CRSS for contraction twins is assumed to be constant with temperature at $13 \mathrm{MPa}$ [39]. If the fraction of initial slip relating to a particular mode is assumed to be proportional to the CRSS, then while the CRSS for twinning does not change with temperature, the relative amount of slip will change slightly as depicted in Figure 6a. The observed trend in slip activity obtained from the GNDs calculated in the tested specimens is slightly upwards as seen in Figure 6b and 6c. This could possibly point to a need for review of the assumptions made in the model used for simulations. The scattering noticed in Figure 6c at initial temperatures can be attributed to low quality scans. However at higher temperatures for the same test specimen an upward trend similar to the one in the 6 mm test specimen is observed.

\section{Conclusions}

Biaxial forming experiments over the temperature range from $25-150^{\circ} \mathrm{C}$ were carried out on a double action hydraulic press, where the punch strokes of $4 \mathrm{~mm}$ and $6 \mathrm{~mm}$ for used for each temperature. Strain ratios measured by DIC on the surface of the sheet showed that stretching was biaxial throughout each test. Load versus punch stroke curves were similar at both $25^{\circ} \mathrm{C}$ and $50^{\circ} \mathrm{C}$, while the loads began to decrease at $75^{\circ} \mathrm{C}$ and higher. Specimens cut from the pole of each sheet were analyzed for twin density, GND content, and slip activity. Twin densities were not much changed given the scatter in the data over the complete range of forming temperatures. Contraction twins that were initially formed rapidly transformed into secondary (double) twins to accommodate the deformation caused by stretching. The ratio of $<\mathrm{a}>/<\mathrm{c}+\mathrm{a}>$ slip appeared to be relatively constant over the entire range of forming temperatures. However, basal slip decreased mildly over the temperature range, while prismatic and pyramidal slip showed mild increases. The increase in non-basal slip would help in accommodating through thickness strains during biaxial stretching while also resulting in the decreased forming loads that were observed as forming temperatures were increased.

\section{Acknowledgements}

This work was supported by National Science Foundation award CMMI-1404771.

\section{Conflict of Interest}

The authors declare that they have no conflict of interest.

\section{References}

[1] A. Staroselsky, L. Anand,: Int. J. Plast. 19, 1843 (2003). 
[2] E. Martin, L. Capolungo, L.A. Jiang, J.J. Jonas,: Acta Mater. 58, 3970 (2010).

[3] S.R. Agnew, M.H. Yoo, C.N. Tome,: Acta Mater. 49, 4277 (2001).

[4] A. Chapuis, J. Driver,: J. Phys.: Conf. Ser., 240, 012092 (2010).

[5] F.K. Chen, T.B. Huang,: J. Mater. Process. Technol. 142, 643 (2003).

[6] K.F. Zhang, D.L. Yin, D.Z. Wu,: Int. J. Mach. Tools Manuf. 46, 1276 (2006).

[7] V. Tabacaru, N. Oancea,: J. Mater. Process. Technol. 115, 14 (2001).

[8] M.R. Barnett,: Mater. Sci. Eng. A. 464, 1 (2007).

[9] H. Yoshinaga, T. Obara, S. Morozumi,: Mater. Sci. Eng. 12, 255 (1973).

[10] M.H. Yoo,: Metall. Mater. Trans. A. 12, 409 (1981).

[11] J. Scott, M. Miles, D. Fullwood, B. Adams, A. Khosravani, R.K. Mishra,: Metall. Mater. Trans. A. 44, 512 (2012).

[12] T. Al-Samman, G. Gottstein,: Mater. Sci. Eng. A. 488, 406 (2008).

[13] I.J. Beyerlein, L. Capolungo, P.E. Marshall, R.J. McCabe, C.N. Tomé,: Philos. Mag. 90, 2161 (2010).

[14] J. Wang, I.J. Beyerlein, C.N. Tomé,: Scr. Mater. 63, 741 (2010).

[15] L. Capolungo, I.J. Beyerlein,: Phys. Rev. B: Condens. Matter Mater. Phys. 78, 1 (2008).

[16] J. Wang, R.G. Hoagland, J.P. Hirth, L. Capolungo, I.J. Beyerlein, C.N. Tomé,: Scr. Mater. 61 , 903 (2009).

[17] T.M. Rampton,: Dissertation. Brigham Young University, 2015.

[18] I.J. Beyerlein, R.J. McCabe, C.N. Tomé,: J. Mech. Phys. Solids. 59, 988 (2011).

[19] C.J. Gardner, B.L. Adams, J. Basinger, D.T. Fullwood,: Int. J. Plast. 26, 1234 (2010).

[20] E. Hsu, J.E. Carsley, R. Verma: J Mater Eng Perform 17, 288 (2008).

[21] T.J. Ruggles, D.T. Fullwood,: Ultramicroscopy. 133, 8 (2013).

[22] A.J. Wilkinson, G. Meaden, D.J. Dingley,: Mater. Sci. Technol. 22, 1 (2006).

[23] A.J. Wilkinson, G. Meaden, D.J. Dingley,: Ultramicroscopy. 106, 307 (2006).

[24] J.F. Nye,: Acta Metall. 1, 153 (1953). 
[25] E. Kröner,: Arch. Rat. Mech. Anal. 4, 18 (1960).

[26] W. Pantleon,: Scri. Mater. 58, 994 (2008).

[27] S. Sun, B.L. Adams, W.E. King,: Philos. Mag. A. 80, 9 (2000).

[28] D.P. Field,: Microsc Microanal. 11, 52 (2005).

[29] B.S. El-Dasher, B.L. Adams, A.D. Rollett,: Scr. Mater. 48, 141 (2003).

[30] P.D. Littlewood, T.B. Britton, A.J. Wilkinson,: Acta Mater. 59, 6489 (2011).

[31] J.W. Kysar, Y. Saito, M.S. Oztop, D. Lee, W.T. Huh,; Int. J. Plast. 26, 1097 (2010) .

[32] J.W. Kysar, Y.X. Gan, T.L. Morse, X. Chen, M.E. Jones,: J. Mech. Phys. Solids, 55, 1554 (2007).

[33] A. Khosravani, J. Scott, M.P. Miles, D. Fullwood, B.L. Adams, R.K. Mishra,: Int. J. Plast. 45, 160 (2013).

[34] P. Cizek, M.R. Barnett,: Scr. Mater. 59, 959 (2008).

[35] M.R. Barnett, Z. Keshavarz, A.G. Beer, X. Ma,: Acta Mater. 56, 5 (2008).

[36] M. Lentz, A. Behringer, C. Fahrenson, I.J. Beyerlein, W. Reimers,: Metall. Mater. Trans. A. 45a, 4737 (2014).

[37] M. Lentz, R.S. Coelho, B. Camin, C. Fahrenson, N. Schaefer, S. Selve, T. Link, I.J. Beyerlein, W. Reimers,: Mater. Sci. Eng., A. 610, 54 (2014).

[38] M.Knezevic, A. Levinson, R. Harris, R.K. Mishra, R.D. Doherty, S.R. Kalidindi,: Acta Mater. 58, 6230 (2010).

[39] M. Ardeljan, I.J. Beyerlein, B.A. McWilliams, M. Knezevic,: Int. J. Plast. 83, 90 (2016). 